\title{
RELATOS SOBRE "SALAS ALTERNATIVAS DE EDUCAÇÃO DE JOVENS E ADULTOS" PARA PESSOAS COM NECESSIDADES EDUCATIVAS ESPECIAIS: UM OLHAR NO PASSADO COM VISTAS PARA O FUTURO*
}

\author{
Dulce Barros de Almeida, \\ da Universidade Federal de Goiás
}

\begin{abstract}
Resumo: Este artigo discute as alternativas encontradas pela Rede Estadual de Educação de Goiás para o atendimento de jovens e adultos com necessidades educativas especiais no início desse século. Trata-se de uma discussão baseada em pesquisa qualitativa de abordagem descritivo-reflexiva que utilizou como instrumentos de coleta de dados as técnicas de observação, entrevistas e análises de documentos. Objetivou analisar como as Salas Alternativas de Jovens e Adultos (SAEJA) se estruturaram e se desenvolveram para dar suporte às pessoas que historicamente foram marginalizadas e excluídas do sistema educacional brasileiro por não atenderem às suas exigências. Dentre as conclusões encontradas, destaca-se o descaso do governo estadual a essa população-alvo, sobretudo no que se refere à concepção de educação de jovens e adultos com necessidades educativas especiais, quer sejam por limitações intelectuais, sensoriais ou físicas, que ainda se encontram à margem de uma educação adequada e de qualidade.
\end{abstract}

Palavras-chave: Salas Alternativas. Jovens e Adultos. Pessoas com Necessidades Educativas Especiais.

INTRODUÇÃO

Este artigo baseia-se em um recorte de pesquisa realizada para a elaboração da tese de doutorado "Do especial ao inclusivo? Um estudo da proposta de inclusão escolar da rede estadual de Goiás, no município de

\footnotetext{
* Artigo recebido em 09/06/2011 e aprovado em 03/09/2011.
} 
Goiânia", defendida e aprovada pela Universidade Estadual de Campinas UNICAMP - em 2003.

A justificativa para esse recorte tem como fundamento a contribuição que se pretende dar aos estudos que estão sendo aprofundados cada vez mais por especialistas da área sobre as situações em que se encontram as pessoas jovens e adultas acometidas por algum tipo de deficiência, que as levam à categoria de pessoas com necessidades educativas especiais no ensino brasileiro.

Para Lajonquière (2001, p. 50), falar em deficiente ou em necessidades especiais não há diferença alguma, pois "o déficit é uma falta a ser apagada por reeducação ou reabilitação enquanto a necessidade é uma falta a ser satisfeita com a educação". Assim, para este autor, mudam-se apenas os nomes, mas as ideias permanecem.

Os dados foram coletados em seis salas de aula de escolas estaduais consideradas como "inclusivas e de referência", por meio da observação participante nos períodos matutino, vespertino e noturno; da análise de documentos primários e secundários e de entrevistas semiestruturadas realizadas tanto com professores como com gestores responsáveis, direta ou indiretamente, pelo desenvolvimento dessas salas alternativas para o atendimento de jovens e adultos. Procurou-se compreender como foi possível a estruturação dessas salas de aula em um contexto educacional considerado "oficialmente" inclusivo pelo governo estadual.

Respostas convincentes para essa questão não são fáceis, entretanto, bastou consultar os documentos vigentes tanto em âmbito nacional quanto regional, para saber como elas foram sendo legitimadas.

No Informativo 001/2000 do Gabinete da então Superintendência de Ensino Especial da Secretaria Estadual de Educação (SUEE/SEE), encontra-se uma explicação para a existência dessas salas. Elas se incluem no Projeto Diversidades - uma alternativa inclusiva de jovens e adultos com necessidades especiais, elaborado pela SUEE. No corpo do projeto, fica esclarecido que se trata de uma parceria entre a Superintendência de Ensino Especial e a então Superintendência de Ensino a Distância e Continuada também vinculada à Secretaria Estadual de Educação (SEADEC/SEE). Suas proposições assim são definidas:

Propomos uma adaptação do Programa de Educação de Jovens e Adultos para pessoas com necessidades educacionais especiais, que apresentam defasagem idade/série. Isto se dará através da implantação de salas alternativas para viabilização deste atendimento aos alunos acima de 12 anos, com deficiências, dificuldades de aprendizagem ou que não tiveram acesso à es- 
colarização em idade própria. Deverão ser atendidos inicialmente, os alunos de $1^{\mathrm{a}}$ a $4^{\mathrm{a}}$ séries do Ensino Fundamental, em turmas inclusivas compostas por no mínimo 12 e no máximo 15 alunos, agrupados numa sala de $1^{\text {a }}$ e $2^{\text {a }}$ séries e outra de $3^{\mathrm{a}}$ e $4^{\mathrm{a}}$ séries. A formação das turmas deverá obedecer aos princípios da educação inclusiva, numa perspectiva de atendimento à diversidade. Os professores que assumirem estas turmas deverão ter habilitação para o ensino fundamental de $1^{\mathrm{a}} \mathrm{a} 4^{\mathrm{a}}$ séries, preferencialmente pedagogos. As salas deverão funcionar nos turnos matutino e vespertino. No noturno, somente quando houver demanda suficiente de alunos em idade permitida pela legislação vigente e aquiescência dos pais ou responsáveis. O currículo seguirá adaptações necessárias à realidade dos alunos. Os conteúdos serão trabalhados de forma dinâmica, utilizando métodos adequados, recursos da comunidade, tais como: arte-educação, esporte e lazer, informática educacional e outros, sempre que possível. O processo avaliativo dos alunos compreenderá o respeito aos diferentes ritmos de aprendizagem. Será feito de maneira sistemática, descritiva e contínua, servindo também como instrumento norteador do planejamento e posturas didático - pedagógicas dos educadores. A aprovação dos alunos respeitará os processos legais de seriação, conforme a produtividade dos mesmos, assegurando a legalidade desta sala. O projeto contará com um adendo anexado ao Programa original, com aprovação do Conselho Estadual de Educação. (GOIÁS/SEE/SUEE, 2000, p. 1-2, grifo nosso)

A SUEE/SEE utilizou a Lei Diretrizes e Bases da Educação Nacional, Lei n. 9.394/96, como respaldo legal para a criação das SAEJA, pois no Cap. II, Seção V, art. 37, parágrafo 1, recomenda:

Os sistemas de ensino assegurarão gratuitamente aos jovens e aos adultos, que não puderam efetuar os estudos na idade regular, oportunidades educacionais apropriadas, consideradas as características do alunado, seus interesses, condições de vida e de trabalho, mediante cursos e exames.

As Diretrizes Nacionais para a Educação Especial na Educação Básica, do CNE/CEB, 2001, também recomendam a criação de classes especiais, mesmo que extraordinariamente. Desse modo, fica respaldado todo tipo de iniciativa que cria no ensino regular modalidades de atendimentos segregados para as pessoas que apresentam necessidades educacionais especiais. No caso das SAEJA, o argumento da SUEE para sua criação é o de incluir alunos jovens e adultos com necessidades especiais na escolarização, mas praticamente em todo o Estado de Goiás, os programas regulares de jovens e adultos já são abertos à comunidade.

Vale ressaltar que a maioria dos alunos jovens e adultos que frequentavam as SAEJA estudaram, quando crianças, em escolas especiais ou classes 
especiais com o objetivo de serem escolarizados e, se possível, incluídos no sistema educacional regular. Mas, é possível aferir que, como a prioridade do ensino especial em Goiás e no Brasil, nas décadas anteriores, resumia-se ao atendimento clínico e não ao educacional, esse objetivo não foi alcançado.

É importante esclarecer que não se teve como proposta ou objetivo, na elaboração desse artigo, a atualização de como essas salas alternativas se encontram hoje no âmbito da Secretaria Estadual de Educação de Goiás.

O que se pretendeu, de fato, foi o desvelamento de situações de discriminação as pessoas jovens e adultas com necessidades educativas especiais têm vivenciado ainda no início desse século, para que esse passado recente seja evitado e abominado de qualquer política de governo estadual, que tenta mascarar, no seu discurso de democratização, a forma natural e contínua que tem dado à exclusão escolar.

\section{RELATOS DE UMA REALIDADE VIVIDA E OBSERVADA}

A seguir, será apresentada uma síntese das observações feitas em salas alternativas para jovens e adultos com necessidades educativas especiais, registradas em Diários de Campo, assim como algumas análises.

O espaço físico da sala I me causou impacto, pois era totalmente diferente dos demais da própria escola. Percebi que era um local improvisado, pequeno, apesar do número também pequeno de alunos (11). Tanto a direção e coordenação como a própria professora afirmaram que o objetivo desta sala era o de atender, no período matutino, jovens e adultos com deficiência ou não, de forma integrada, que não tiveram oportunidades educacionais anteriormente. Constatei, entretanto, que todos os alunos presentes eram pessoas com deficiência, situavam na faixa etária entre 12 e 31 anos, e oito deles eram egressos de escola ou classe especial. $\mathrm{O}$ argumento da escola se resumia no fato de a família ou de o próprio jovem e/ou adulto, sem deficiência, ter desinteresse em estudar nesta sala, quando percebia o número elevado de pessoas com deficiência no seu interior. Dos 11 alunos matriculados, apenas um era considerado alfabetizado e os outros 10 eram alunos em processo de alfabetização, apesar de três destes ainda serem considerados alunos fracos.

As atividades propostas aos alunos, nesta manhã, resumiram-se em copiar, no caderno, o cabeçalho dado no quadro (nome completo da escola, cidade e data, nome do aluno e da professora); fazer atividades formais de matemática, tais como escrever os números pares de um até 40 e resolver "continhas" $10+5 ; 8+6 ; 7+9 ; 12+8 ; 15+7$ e trabalho com massinhas coloridas para que os alunos pudessem desenvolver sua criatividade, modelando 
alguma coisa que fosse do interesse deles. Nas atividades envolvendo operações, os alunos utilizavam muitos materiais concretos, tais como tampinhas de garrafa, bolinhas e pauzinhos de picolé. Como tarefa de casa foram dadas mais continhas. Tudo era registrado diariamente no Diário de Classe. No decorrer do recreio, os alunos não demonstraram nenhum tipo de entrosamento com os demais colegas no pátio, ficaram à margem do contexto escolar.

Na leitura realizada, concebeu-se que, neste dia, essa sala funcionou de forma tradicional em tudo: conteúdo, material didático, metodologia, distribuição de carteiras (apesar do pequeno espaço físico), utilização do quadro, do diário, dos cadernos... Não foi percebido nenhum tipo de inovação que pudesse ser descrita como destaque e que justificasse a sua criação. Apesar da assistência, das orientações individuais e da preocupação com todos os alunos, a professora demonstrou não estar mobilizada para mudanças relacionadas com sua prática pedagógica ou com qualquer outro tipo de transformação em sua sala de aula.

Na SAEJA II, todos os alunos tinham algum tipo de deficiência e situavam-se na faixa etária entre 10 e 18 anos de idade. Nesta sala, algumas situações foram classificadas como inaceitáveis: os alunos não se respeitavam, gritavam o tempo todo, ofendiam uns aos outros por meio de palavras e até se agrediam fisicamente. E a atitude da professora diante desta situação? A impressão causada foi a de que ela não conseguia impor limites aos seus alunos, pois os comportamentos estereotipados se repetiam com frequência. Ela se limitava a vigiar os alunos e dar assistência aos "mais fracos", adotando uma postura paternalista, sem demonstração de compromisso pedagógico. Não foi observada nenhuma atividade interessante selecionada, iniciativa ou criatividade para a mudança do contexto pedagógico da sala de aula. Um fato que também chamou a atenção foi a presença de uma criança com idade inferior a 10 anos nesta sala. Daí a indagação: os critérios para se frequentar esta classe não estão sendo seguidos? Por quê? Pelos documentos das SAEJA, a idade mínima para que se possa frequentá-las é de 12 anos, como exceção e se for extremamente necessário. O que justificaria então o ingresso de crianças nesta sala direcionada a jovens e adultos e ainda em uma escola "inclusiva e de referência"?

Os alunos de outra dessas salas observadas, denominada III, eram todos adultos com idade entre 21 e 56 anos. O espaço físico da sala de aula se diferenciava das demais desta escola por ser bem menor, inclusive para acomodar os 14 alunos presentes. Apesar de os alunos em geral demonstrarem interesses similares em diversos assuntos, o trabalho realizado pela professora 
era individualizado: os alunos eram atendidos isoladamente, sem trocas de experiências ou ajudas entre eles. As atividades eram descontextualizadas e sem sentido para um adulto. Moças e donas de casa faziam atividades de coordenação motora sem nenhuma articulação com conteúdos interessantes e copiavam numerais (de 1 a 5) sem sentido expresso e também totalmente de forma descontextualizada. Concebe-se que, apesar de todo o interesse e carinho demonstrado pela professora em sala de aula, o trabalho realizado com os adultos deveria ser muito diferente, mais condizente com sua realidade, mais estimulante e com maior compromisso pedagógico. Mais uma vez foi demonstrado que as atitudes paternalistas/assistencialistas por parte dos professores nestas SAEJA têm sido constantes.

Não se pode negar a importância de se estabelecer mecanismos e instrumentos que assegurem às pessoas o pleno exercício de seus direitos básicos que proporcionem o seu bem-estar pessoal, social, econômico e humano, seja ela uma pessoa com necessidades educativas especiais ou não (ALMEIDA e TEIXEIRA, 2011).

A situação foi ainda muito mais séria em uma SAEJA, denominada IV, em que, praticamente, todos os seus alunos eram jovens com grandes possibilidades de aprendizagem, inclusive com dons artísticos elevados. Mas como estavam em um ambiente segregado de uma Escola Inclusiva de Referência (EIR), a descrença dos profissionais da escola como um todo em relação ao aprendizado deles pareceu ser total.

Entende-se que todos esses alunos deveriam ser conduzidos para as turmas seriadas da própria escola ou para as salas de Educação de Jovens e Adultos/EJA da própria rede estadual, que na ocasião nada as ligava com as SAEJA, para minimizar os possíveis danos causados pela escola a estes jovens. Acredita-se que os atos de indisciplina, assim como os comportamentos estereotipados que foram presenciados, poderiam ser evitados se os alunos convivessem em um ambiente "normal", menos estigmatizante e segregado.

Alguns alunos com dificuldades de aprendizagem demonstraram, até mesmo, rejeição pela turma que frequentavam e, sobretudo, pelos próprios colegas mais comprometidos intelectualmente. Houve diversas demonstrações de que eles se sentiam envergonhados por estar ali, o que era completamente compreensível.

Em vista dessa situação, por exemplo, na qual há alunos com habilidades para artes, questiona-se se os estudos sobre a Teoria das Inteligências Múltiplas, considerados de grande importância para os Setores de Apoio à Inclusão da SUEE/SEE, estavam sendo levados em conta nas práticas pedagógicas desenvolvidas em sala de aula. Constatou-se naquele contexto que não! 
Essa Teoria - produzida por Gardner em 1983 e aperfeiçoada por Armstrong em 1987, 1994 e 1996 - proporciona uma estrutura útil para a identificação de estratégias de ensino em multiníveis, com base nas áreas que a constituem: Inteligência Linguística, Inteligência Lógico-Matemática, Inteligência Espacial, Inteligência Corporal-Cinestésica, Inteligência Musical, Inteligência Interpessoal, Inteligência Intrapessoal e a Inteligência Naturalística.

Se as aulas, nessas salas alternativas, fossem fundamentadas na Teoria das Inteligências Múltiplas, com certeza, os professores teriam, como nos afirmam Stainback e Stainback (1999, p. 148), "maior chance de obter êxito no ensino de todos os seus alunos, incluindo aqueles que foram classificados e rotulados como tendo diferenças e deficiências, como estando sob risco ou como difíceis de ensinar".

No decorrer de toda a aula, nesta sala, apesar das dificuldades encontradas, a professora demonstrou interesse por todos os alunos e conseguiu desenvolver algumas atividades interessantes, estimulantes e criativas. Em seu depoimento, entretanto, declarou sentir-se abandonada e sem apoio. Ela declarou, inclusive, não concordar com o funcionamento da SAEJA, entendendo-a como segregadora, especialmente por se encontrar no interior de uma escola inclusiva.

Todos os alunos de outra SAEJA denominada $\mathrm{V}$, tinham algum tipo de deficiência e se situavam na faixa etária entre 14 e 30 anos. Observou-se com estranheza o descompromisso pedagógico demonstrado pela professora diante dos seus alunos. Em seus depoimentos, evidenciou-se que aqueles alunos estavam no lugar certo, pois "em sala regular, ninguém vai dar conta de muita coisa". Ela acreditava que os alunos ali presentes, assim como outros, precisam ser "bem preparados" por professores que entendem o ensino especial, como ela, para que sejam incluídos no ensino regular.

As atividades trabalhadas nesta SAEJA foram bem recebidas pelos alunos, talvez por acomodação, pois não traziam qualquer tipo de dificuldade ou desafio. Os alunos diziam o que queriam fazer e eram atendidos de imediato pela professora, ninguém era contrariado ou estimulado a inovações.

Esta realidade observada remete mais uma vez às concepções de integração escolar vigentes nas décadas de 1970 e 1980 que continuam fazendo parte do ideário de muitos professores, mesmo entre aqueles que se encontram em escolas consideradas inclusivas: apenas o aluno precisa ser preparado e modificado para se adequar à escola, a culpa é totalmente dele, caso contrário, jamais sairá do estado de marginalização em que se encontra.

Na última SAEJA observada, denominada VI, a situação não foi alterada. Estavam presentes 16 alunos, dos quais 15 tinham algum tipo de 
deficiência. Encontravam-se na faixa etária entre 12 e 19 anos de idade, excetuando-se dois, com 39 e 51 anos. Praticamente todos esses alunos eram egressos de escolas ou classe especiais. $O$ único aluno estudante sem qualquer tipo de deficiência era um senhor com mais de 50 anos de idade tratado como criança, executando as atividades escolares junto a adolescentes e jovens entre 12 e 19 anos!

Pelo que foi afirmado pela coordenadora da escola, houve continuidade do ensino especial para o atendimento dos alunos jovens e adultos com deficiência nesta escola, mas em outra modalidade, agora, sob a denominação de Sala Alternativa de Educação de Jovens e Adultos (SAEJA). Esta afirmação pôde ser constatada em cinco das seis SAEJA observadas neste estudo.

\section{TENTANDO NÃO CONCLUIR, MAS PENSANDO NO FUTURO...}

Percebe-se que a criação dessas salas continuou discriminando, segregando e excluindo alunos, apesar do discurso contrário da SUEE/SEE; as SAEJA contradizem a proposta de inclusão por ser uma modalidade especial para atender a pessoas que histórica e culturalmente já tinham uma longa experiência de discriminação e marginalização no meio escolar. Isso a partir de 12 anos de idade!

Como não se verificou nas seis salas observadas, praticamente, nenhum trabalho pedagógico escolar definido e sistematizado voltado para o atendimento adequado de alunos jovens e adultos, não se pode tecer comentários a respeito da sua proposta curricular. Os professores destas salas pareciam estar fazendo o que podiam e o que sabiam, pois se sentiam comprometidos com os alunos, muito mais por questões pessoais e paternalistas do que por questões pedagógicas. Mas isso seria suficiente? A maioria destes professores havia atuado em classes especiais que funcionavam nessas mesmas escolas antes de se tornarem EIR e com os mesmos alunos que não foram incluídos nas turmas escolares regulares. $\mathrm{O}$ que mudou?

Para os professores dessas salas, nem a SUEE nem a SEADEC assumiam as SAEJA de forma sistematizada; havia ali um verdadeiro jogo de empurra-empurra.

Para entender e conhecer melhor a proposta das SAEJA, idealizada pela SUEE, dois assessores deste órgão foram entrevistados e afirmaram que

estas salas foram criadas para dar mais oportunidades aos alunos jovens e adultos com deficiência de se escolarizarem, por não terem tido oportunidades de estudar em escola regular na idade escolar. 
Segundo esses assessores, as SAEJA deviam seguir as mesmas diretrizes da SEADEC e adotar estratégias para atender às necessidades dos alunos especiais. Nas palavras desses assessores, "proposta alternativa não é para ficar para sempre, é uma transição para ser trabalhada junto". Para eles, as SAEJA se justificam pelo fato de as salas de jovens e adultos da SEE serem muito cheias, funcionarem no período noturno e sofrerem muita resistência dos profissionais de educação em trabalhar com alunos com deficiência.

A SUEE pretendia, na ocasião, capacitar os professores das salas de jovens e adultos para trabalhar com os alunos que têm dificuldades. Para tanto, buscaria parcerias e envolvimento da SEADEC. No futuro, a SUEE, segundo seus assessores, espera que os alunos das salas alternativas possam ser encaminhados para outros programas da SEE, como o Supletivo ou o Acelera.

Numa tentativa de obter maiores esclarecimentos a respeito das SAEJA, procurou-se uma assessora da SEADEC. Em conversa informal, ela afirmou que as SAEJA são uma "invenção" do ensino especial e que elas não têm nada a ver com o Programa de Jovens e Adultos desenvolvido pela Superintendência de Ensino a Distância e Educação Continuada.

Diante dessas constatações, as responsabilidades e os compromissos com os alunos jovens e adultos com necessidades educativas especiais, por parte dos gestores responsáveis por essas salas, ficavam difíceis de serem expressos.

O depoimento de uma das diretoras da escola onde foi implantada uma SAEJA evidencia o descaso por estas salas, ao afirmar que todos os problemas detectados são tanto de ordem institucional quanto operacional, em virtude das diretrizes equivocadas da SUEE e das indefinições da SEADEC. Ela afirmou ainda que,

na verdade, nenhum órgão da SEE quer assumir esta sala. Ela só existe por insistência dos pais e da própria escola que não tem onde colocar os alunos deficientes que não acompanham as salas regulares.

Com este depoimento, constataram-se uma vez mais as dificuldades que as EIR têm de compreender como a inclusão deve ser operacionalizada, apesar de tantos cursos e tantas orientações terem sido repassadas pelo ensino especial.

A inclusão requer mudanças sistemáticas na maneira como as escolas são organizadas e administradas, há necessidade de alterações envolvendo, sobretudo, a comunidade escolar. Trabalhar com a diferença, no sentido pleno, é entender que o ensino, o apoio, os recursos didático-pedagógicos, a metodologia, a proposta curricular e a própria avaliação da aprendizagem devem beneficiar a todos e não apenas a"alguns". É preciso enfrentar o desafio 
de trabalhar com as diferenças para atender a diversidade que se faz presente nas escolas em geral.

As dificuldades das EIR também ocorrem quando se solicita qualquer tipo de apoio para as SAEJA, pois não se sabe claramente quais são os verdadeiros responsáveis por elas. Enquanto as orientações e diretrizes de atendimento aos alunos e professores são dadas pela SUEE, a SEADEC, que deveria ser a responsável institucional por essas salas, cala-se e se omite completamente.

A única inovação trazida pelas $S A E J A$, em relação às classes especiais, foi o fato de se direcionarem (ainda que no papel) apenas a jovens e adultos, mas nelas constatamos a presença de alunos com 12 anos de idade e com o respaldo do próprio ensino especial. Por que 12 anos se a idade limite para a matrícula no Ensino Fundamental ainda é de 14 anos? E na EJA a partir dos 15 anos?

Ressalta-se, por contradição, que também havia um sentimento de aprovação, nas escolas pesquisadas, em relação à criação das SAEJA, pois elas constituíam uma das opções das escolas para os alunos considerados "difíceis" de serem incluídos, segundo alguns de seus diretores, coordenadores e professores, em razão da imaturidade, idade cronológica avançada, do nível acadêmico deficitário e comportamento inadequado.

Enfim, há sempre uma alternativa de se resolver os problemas dos alunos jovens e adultos com necessidades educativas especiais, mesmo em uma escola que se diz inclusiva e com a aprovação da Secretaria de Estadual de Educação, que insiste em afirmar, em seus discursos, a integração de todos os seus programas escolares.

Entende-se que se houvesse uma melhor articulação e integração entre os órgãos da Secretaria Estadual de Educação de Goiás seria possível a transformação da política educacional de atendimento aos jovens e adultos, para que todos pudessem ser beneficiados, sem alternativas que acabam se constituindo em discriminação, marginalização, e, em consequência, exclusão de toda ordem.

A situação de exclusão em que se encontram muitos jovens e adultos, com necessidades educativas especiais ou não, é histórica e cultural. Apesar de alguns avanços nesse sentido, sobretudo graças à ação de grupos populares, de organizações não governamentais e de profissionais comprometidos com a área, a educação desses alunos no Brasil ainda continua sendo um verdadeiro desafio para as nossas políticas de governo e, inclusive, públicas. A este respeito, Soares (1999, p. 30) assim se pronuncia: 
A educação de jovens e adultos é um conceito mais ampliado, mais próximo da realidade da população que a demanda. Não se trata de mera transmissão de conhecimentos nem de projetos aligeirados com vistas à rápida aquisição do diploma. Educação é processo, é conhecimento, é reflexão, é interação, que requerem 'tempo' e 'espaços' para serem vivenciados.

Rodrigues (2000) complementa essa concepção ao esclarecer que a Educação de Jovens e Adultos deve ser compreendida como direito público subjetivo de todo cidadão a uma educação de qualidade ao longo da vida, como um bem sócio-histórico e culturalmente produzido, com finalidades e funções específicas, que precisa efetivar a função reparadora da dívida histórica-social com aqueles que não tiveram acesso à educação ou dela foram excluídos, bem como contemplar as funções equalizadora e qualificadora. Trata-se de uma educação que respeite as características dos sujeitos a que se destina, enquanto modalidade, com formas de organização adequadas às suas necessidades e disponibilidades, garantindo-se o acesso e a permanência aos alunos trabalhadores, e compete ao Estado o dever de oferecer as condições necessárias para a execução desta modalidade de ensino.

A concepção que permeou toda a pesquisa realizada partiu do princípio de que toda ação educativa deve ter como eixo o convívio com as diferenças, a aprendizagem como experiência relacional, participativa que produz sentido para o aluno, pois contempla a sua subjetividade, embora construída no coletivo das salas de aula.

A inclusão, como nos esclarece Mantoan (2002, p. 86), "é um conceito que emerge da complexidade, dado que a interação entre as diferenças humanas, o contato e o compartilhamento dessas singularidades compõem a sua ideia matriz".

Concretizar, de fato, a inclusão de pessoas com necessidades especiais, quer seja com crianças, jovens ou adultos, conforme afirmação que tem sido feita frequentemente por Almeida (2003) constitui um grande desafio, pois envolve mudanças na concepção de sociedade, de homem, de educação e de escola. Mudar concepções já cristalizadas e arraigadas em nome de outro modelo de educação não é uma tarefa simples e fácil, sobretudo quando essas mudanças vão beneficiar pessoas que foram historicamente injustiçadas, marginalizadas e excluídas da sociedade, e, em consequência, da escola. 


\section{REPORTS ON 'ALTERNATIVE CLASSROOMS FOR YOUTH AND ADULT EDUCATION' FOR PEOPLE WITH SPECIAL EDUCATIONAL NEEDS: A LOOK INTO THE PAST WITH AN EYE TO THE FUTURE}

ABSTRACT: This article discusses the alternatives adopted by the Goiás State Education Network at the beginning of this century for the care of young people and adults with special educational needs. The discussion is based on qualitative research of a descriptive and reflexive nature in which observation techniques, interviews and documental analyses were used as data collecting tools. It sets out to analyze how the 'Alternative Classrooms for Youth and Adult Education' were structured and organized to support people who had been historically marginalized and excluded from the Brazilian educational system because they did not meet its requirements. Among its conclusions, the study highlights State government indifference towards this target group, particularly in terms of the education of young people and adults with special educational needs, whether intellectual, sensorial or physical, who are still on the sidelines when it comes to adequate quality education.

KeYwords: Alternative classrooms. Young people and adults. People with special educational needs.

\section{REFERÊNCIAS}

ALMEIDA, Dulce Barros de. Do especial ao inclusivo? Um estudo da proposta de inclusão escolar da rede estadual de Goiás, no município de Goiânia. Tese (Doutorado em Educação), Faculdade de Educação, Universidade Estadual de Campinas, Campinas: SP, 2003.

ALMEIDA, Dulce Barros de; TEIXEIRA, Ricardo A. Gonçalves. Contexto educacional complexo e diverso a partir de uma análise interpretativa dos aspectos legais que subsidiam propostas educativas inclusivas. In: SUANNO, Marilza V. Rosa (Org.). Didática e escola em uma sociedade complexa. Goiânia: CEPED, 2011.

BRASIL/MEC. Lei de Diretrizes e Bases da Educação Nacional, Lei n. 9.394. Brasília/ DF, 1996.

BRASIL/MEC/SEESP. Resolução CNE/CEB n. 2. Diretrizes Nacionais para a Educação Especial na Educação Básica. Brasília/DF, 2001.

GOIÁS/SEE/SUEE. Projeto Diversidades: uma alternativa inclusive para a educação de jovens e adultos com necessidades especiais. 2000 (mimeo).

LAJONQUIÈRE, Leandro de. Duas notas psicanalíticas sobre as crianças com "necessidades educativas especiais". In: Pro-posições, v. 12, n. 2-3, p. 35-36, jul./nov. 2001. Revista Quadrimestral da FE/Unicamp. p. 47-59.

MANTOAN, Maria Teresa. Eglér. Produção do conhecimento para a abertura das escolas às diferenças: a contribuição do LEPED (Unicamp). In: ROSA, D. E. G.; SOUZA, V. C. 
Políticas organizativas e curriculares, educação inclusiva e formação de professores - XI ENDIPE. Rio de Janeiro: DP\&A e Goiânia: Alternativa, 2002. p. 79-93.

RODRIGUES, Maria Emilia de Castro. A Prática do Professor na Educação de Adolescentes, Jovens e Adultos: a experiência do Projeto AJA de Goiânia-GO. Goiânia, GO, 2000. Disponível em: http://forumeja.org.br/go/sites/forumeja.org.br.go/files/dissertacaomariaemilia.pdf. Acesso em: 30 jul. 2011.

SOARES, Leôncio José Gomes. Processo de inclusão/exclusão na educação de jovens e adultos. In: Revista Presença Pedagógica. Editora Dimensão, v. 5, n. 30, nov./dez. 1999. p. 24-33.

STAINBACK, Susan; STAINBACK, William. Inclusão- um guia para educadores. Trad. de Magda França Lopes. Porto Alegre: Artes Médicas Sul, 1999.

Dulce Barros de Almeida iniciou suas atividades como docente em 1972, junto a crianças, jovens e adultos acometidos por algum tipo de deficiência, em Belo Horizonte/MG. É licenciada pela PUC/Minas; Especialista em Educação Especial pela PUC/GO; Mestre em Educação Escolar Brasileira pela FE/UFG e Doutora em Educação pela Unicamp/SP. Atua nas áreas de Didática e Estágio, Metodologia do Ensino Superior, Educação Especial e Inclusão Escolar. Atualmente desenvolve suas atividades como professora colaboradora do Programa de Pós-Graduação da FE/UFG (Mestrado e Doutorado) na Linha de Pesquisa - Formação e Profissionalização Docente; como Pesquisadora vinculada ao Diretório de Pesquisa da Unicamp - Laboratório de Estudos e Pesquisas em Ensino e Diversidade - LEPED, desde 1999 e como coordenadora do Núcleo de Acessibilidade da UFG a partir de setembro/2011.

Email: dubalmei@hotmail.com 